Informatika i sistemy upravleniya. - 2018. - No. 3(57). - P. 93-103.

Eremin E.L. (ereminel@mail.ru)

Amur state university

\title{
A COMBINED SYSTEM WITH AN IMPLICIT STANDARD FOR A CLASS OF UNCERTAIN A PRIORI SINGLE-CHANNEL NON-AFFINE CONTROL PLANTS ON THE SET OF OPERATION STATES
}

Under the conditions of structural, functional and parametric uncertainty, the synthesis of algorithms of the combined control system for a class of single-channel non-affine plants with a step-by-step variable is carried outunder condition of limited external interference and measurement of only the controlled variable. Based on the hyperstability criterion, $L$-dissipativity conditions, the passification method andon the application of the implicit reference model and two correction filters in the control system, it is proved, that for the non-affine object studied on the set of operation states (caused by its arbitrary switching), it is possible to create a control law that ensures the achievement of the goal. The results of the simulation modeling showed considerably high efficiency of tracking the reference signal for a priori uncertain plants with non-affinity for control.

Keywords: a priori structural-functional-parametric uncertainty, single-channel non-affine control plant with step-by-step variable dynamics, implicit reference model, specifying and output correction filters, combined control system, hyperstability criterion, $L$-dissipativity conditions, passification method.

DOI:10.22250/isu.2018.57.93-103

\section{For citation:}

Eremin E.L. A COMBINED SYSTEM WITH AN IMPLICIT STANDARD FOR A CLASS OF UNCERTAIN A PRIORI SINGLE-CHANNEL NON-AFFINE CONTROL PLANTS ON THE SET OF OPERATION STATES // Informatika i sistemy upravleniya. - 2018. - No. 3(57). - P. 93-103. 